\title{
ANÁLISIS ARQUEOLÓGICO E INTERPRETACIÓN DE LOS ESPACIOS FUNERARIOS DEL OPPIDUM DE GIRIBAILE EN EL TERRITORIO DEL VALLE DEL GUADALIMAR (JAÉN)
}

\author{
POR \\ LUIS MARÍA GUTIÉRREZ SOLER ${ }^{1}$ \\ Universidad de Jaén \\ ISABEL IZQUIERDO PERAILE ${ }^{2}$ \\ CSIC. Madrid
}

PALABRAS CLAVE: Cultura ibérica. Necrópolis ibérica. Paisaje funerario. Oppidum ibérico de Giribaile. Jaén (provincia). Monumento funerario.

KEYWORDS: Iberian culture. Iberian necropole. Funerary landscape. Giribaile Iberian oppidum. Jaén (provincia). Funerary monument.

\section{RESUMEN}

Presentamos en este trabajo el espacio funerario correspondiente al asentamiento ibérico de Giribaile (Vilches, Jaén), que entra dentro de la categoría de los grandes oppida del Alto Guadalquivir. Mediante prospección se han definido tres sectores de necrópolis que rodean la base de la meseta fortificada donde se sitúa el oppidum. En el sector funerario denominado de la plataforma inferior se ha documentado la base de un monumento de forma cuadrangular y dimensiones considerables, dotado de una cornisa con moldura de gola lisa. La presencia de esta construcción ofrece paralelos con otros monumentos funerarios ibéricos del área del Guadalquivir y, en general, del sureste peninsular.

\section{SUMMARY}

Study of the «funerary space» of the Iberian settlement of Giribaile (modern Vilches, prov. Jaén). The site can be considered as important as other great Iberian oppida in the region of the Alto Guadalquivir. The survey has define three different areas of the necropolis, all three around the fortified plain of the oppidum. It is specially relevant a funerary monument of quadrangular structure found in the so-called «plataforma inferior». The monument is crowned by an Egyptian throat or hollow gorge, and can be paralleled with other Iberian funerary monuments of the Guadalquivir valley and also with other iberian tombs in the south-east area of the Iberian Peninsula.

1 Centro Andaluz de Arqueología Ibérica. Profesor asociado del Área de Arqueología. E-mail: Imsoler@ujaen.es

2 Instituto de Historia. Becaria postdoctoral por la Comunidad de Madrid. E-mail: cehi309@ceh.csic.es

Agradecemos a la Prof. C. Aranegui la lectura y sugerencias a este texto.

\section{EL OPPIDUM DE GIRIBAILE EN SU TERRI- TORIO}

La meseta de Giribaile se localiza en la confluencia entre los ríos Guadalimar y Guadalén, en el término municipal de Vilches, cerca de Miralrío ${ }^{3}$. Con relación al paisaje circundante, Giribaile ocupa una posición destacada ${ }^{4}$, de dominio, que le permite ejercer un importante control visual sobre su entorno más inmediato, de configuración variable. La vega del Guadalén dispone de una amplia zona cultivable que topográficamente se cierra en las primeras estribaciones del piedemonte de Sierra Morena, ricas en filones de galenas argentíferas, explotados con seguridad al menos desde época ibérica (Domergue, 1987, 292). Hacia el Guadalimar, el valle se estrecha y queda encajado por dos pasos naturales, denominados los Escuderos y el Vado de las Hoyas, resultado del afloramiento del granito que forma la base geológica, y por la cuesta de la Loma de Úbeda.

Con respecto a la documentación arqueológica, los resultados de las recientes prospecciones llevadas a cabo en el entorno del oppidum de Giribaile han sacado a la luz la existencia de un denso patrón de poblamiento compuesto por casi un centenar de pequeños y grandes asentamientos que se distribuyen a lo largo del valle (figura 1). Se localizan preferentemente en las terrazas más próximas al Gua-

3 Se asienta sobre una formación geológica de época miocena, fracturada por una falla. El lecho de este antiguo mar actualmente está rodeado de ricos acuíferos y manantiales que se concentran a la altura de las cuevas excavadas en la base del farallón de roca sobre el que se alza la meseta. Estos condicionamientos la convierten en un terreno con un bajo rendimiento agrícola, aunque apto para el desarrollo de ganadero y otros aprovechamientos agropecuarios de gran importancia en la economía antigua.

${ }^{4}$ Un vértice geodésico que marca una altitud de $522 \mathrm{~m}$ fue instalado en el punto más elevado de la muralla. 


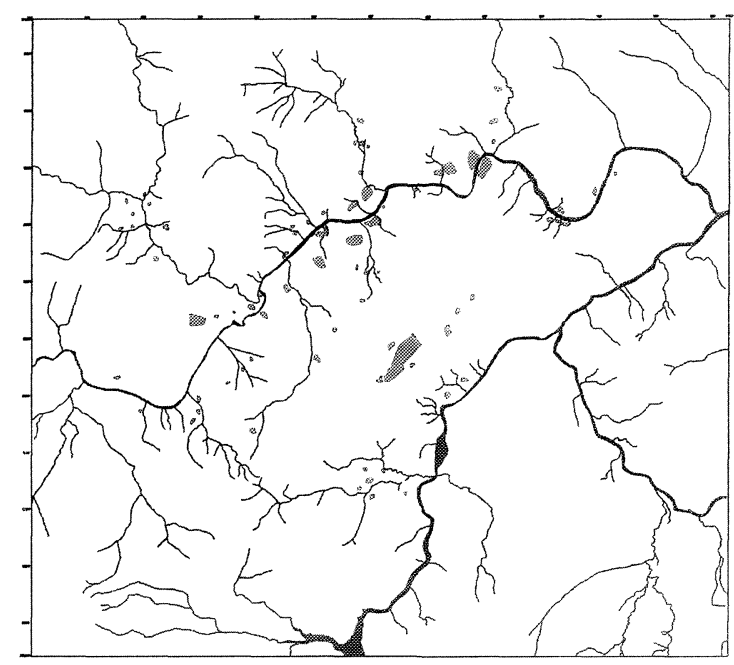

Fig. 1.-Dispersión del poblamiento de época íbero-romana en el valle del Guadalimar (Jaén).

dalimar, en la confluencia con los arroyos secundarios, de segundo y tercer orden, y siguiendo el curso de éstos hasta que dejan de tener un contacto visual con Giribaile. El repertorio de cultura material que presentan los asentamientos de este territorio es bastante reducido y repetitivo, predominando las ánforas. Su análisis comparado con muestras procedentes del oppidum y el cercano santuario de los Altos del Sotillo (Castellar de Santisteban, Jaén), permite avanzar una datación posterior al siglo III a.C., determinando un horizonte del ibérico tardío, poco conocido hasta el momento, que se desarrollaría al finalizar la segunda guerra púnica. La hipótesis que hemos propuesto (Gutiérrez, 1998a) plantea la existencia de una comunidad estipendiaria, dependiente del oppidum de Giribaile, que no se abandona hasta finales del siglo il o principios del I a.C. Este proceso concluye cuando cambian las condiciones en las que se basaban las relaciones que se habían establecido entre Roma y los poderes locales en el área del alto Guadalquivir, produciéndose una crisis generalizada, que tendrá como conclusión la sustitución del oppidum de Giribaile por el de La Monaria, fortificado y en llano, que posiblemente no permaneciera habitado más de cincuenta años (Gutiérrez et alii, 1999b), cuyo urbanismo refleja la utilización de un módulo de casa con patio, similar al que podemos encontrar cerca de la muralla. El último momento estudiado en la evolución del antiguo territorio dependiente de Giribaile permite definir un nuevo horizonte arqueológico formado por un entramado de villae rusticae altoimperiales, de época flavia, en manos de propietarios privados, que nada tiene que ver con los antiguos principios rec- tores de carácter aristocrático que habían servido de elemento cohesionador durante siglos.

\section{HISTORIA DE LA INVESTIGACIÓN, SE- CUENCIA Y CARACTERIZACIÓN AR- QUEOLÓGICA}

El oppidum de Giribaile puede ser considerado, con sus más de 18 ha de meseta fortificada, uno de los grandes poblados ibéricos de la provincia de Jaén (Ruiz y Molinos, 1993, 113), articulando junto con Cástulo y Olvera un patrón de poblamiento lineal que se vertebra siguiendo el curso del río Guadalimar. La única posible referencia a Giribaile de la que nos queda constancia en las fuentes escritas de la Antigüedad es un breve pasaje del libro segundo de las Vidas Paralelas de Plutarco (Sertorio, 3, 510). Sin embargo, las primeras menciones conocidas sobre este sitio deben enmarcarse en el interés que nace a mediados del siglo XIX por redescubrir las antiguas poblaciones citadas por los escritores clásicos. A semejanza de los grandes viajeros que habían recorrido la provincia de Jaén durante los siglos XVI y XVII, tales como Acursio, Florian de Ocampo, Ambrosio Morales, Jimena Jurado o Argote de Molina, los historiadores decimonónicos ${ }^{5}$ visitaron lugares que aún se evocaban en la memoria popular, a la que no eran ajenas las leyendas medievales. En este sentido, el antiguo nombre del lugar se asociaba al nombre del caballero de Baeza, Gil Bayle o Baylio de Cabrera, señor que dominó estas tierras en el siglo XIII (Góngora, 1982).

Entre 1968 y 1970 se llevó a cabo una intervención arqueológica (Servajean et alii, 1986), excavándose 14 cortes en la zona central del poblado. Poco conocemos de los resultados obtenidos por aquellos años; algunos de los materiales recuperados quedaron depositados en el Museo Provincial de Jaén. Respecto a los diarios de campo, tan sólo nos ha llegado una parte, que hemos ordenado y sistematizado. Desde que la Junta de Andalucía asumió plenas competencias en materia de Patrimonio Histórico, se abre una nueva etapa marcada por el interés de proteger y salvaguardar la riqueza arqueológica de este importante poblado, llevándose a cabo durante el verano de 1986 un campo internacional de trabajo. Recientemente, en 1994, por iniciativa de la Delegación Provincial de Cultura de Jaén, se ha elaborado la documentación técnica necesaria

5 A Manuel de Góngora y Martínez (1822-1884) debemos valiosas descripciones, no sólo del poblado ibérico que ocupa el espolón más septentrional de la meseta, sino también de su entorno más inmediato (Góngora, 1982). 
para la inscripción de Giribaile en el Catálogo General de Patrimonio Histórico Andaluz como Zona Arqueológica. Como parte de este proceso debemos mencionar la realización de las campañas de prospección que, con carácter sistemático (Gutiérrez et alii, 1995) o de urgencia (Royo et alii, 1995), hemos llevado a cabo.

Con respecto a la secuencia, aunque la fase de mayor apogeo corresponde a la etapa ibérica, la primera instalación estable que ha sido constatada arqueológicamente data del Bronce medio y final, tratándose de un poblado de cabañas. Tras el estudio de los materiales procedentes del oppidum (Gutiérrez y Royo, 1999) se ha concluido que no existe una continuidad entre el poblado prehistórico y la ocupación ibérica, que no se puede retrotraer más allá de la primera mitad del siglo IV a.C. En el periodo intermedio entre ambos horizontes arqueológicos, el sitio permanecería deshabitado. De esta forma, Giribaile se mantendría como un oppidum hasta finales del siglo II o comienzos del I a.C., momento en el que sufre una destrucción violenta. Este episodio podría corresponder a una acción de castigo de la guarnición romana que hibernaba en Cástulo a cargo del cónsul Tito Didio en el año 90 a.C. tal como refleja el pasaje de Plutarco que hemos mencionado ( $c f$. supra). En relación a una posible ocupación romana de Giribaile (García-Gelabert, 1988, 417-423), por el momento sólo se han documentado unos pocos fragmentos de terra sigillata hispánica en la meseta, que interpretamos más como resultado del cultivo de estos terrenos por parte de los propietarios de alguna casa rural romana cercana, que como una.ocupación permanente y estable. Un nuevo periodo de esplendor se abre con la ocupación medieval de las cuevas de Giribaile, que se adaptan para cumplir la función de un santuario, un oratorio y un eremitorio, al que también se asocian algunas tumbas excavadas en la roca en los olivares cercanos ${ }^{6}$. El último momento de ocupación debe relacionarse con la recuperación de los valores estratégicos de la meseta de Giribaile. Una primera

${ }^{6}$ De esta forma Giribaile, o para ser más precisos, las cuevas de Giribaile, a las que la tradición relaciona con Spellun$c a$, topónimo medieval, se incorporan a un importante poblamiento del que cada vez se conocen más evidencias en el valle, pudiendo citarse entre otras la cueva de la Veguilla o el oratorio de Valdecanales (Vañó, 1970), representando este conjunto uno de los escasos exponentes de arquitectura religiosa, visigoda o mozárabe, conocidos en Andalucía. Por otra parte, las recientes prospecciones que hemos llevado a cabo en la zona muestran una densa ocupación del llano en época tardorromana y visigoda (Gutiérrez et alii, 1999a), que continuaría durante la etapa emiral con la posible localización de un hisn en Giribaile que sirviera de refugio de todos los pobladores del entorno (Castillo, 1997). lectura de la estratigrafía muraria del castillo parece mostrar la existencia de una arquitectura cristiana que enmascararía una anterior de época islámica. A partir del abandono del castillo, Giribaile no será más que un punto de referencia importante en el paisaje.

Centrándonos en la época ibérica, son escasos los datos para intentar reconstruir el urbanismo del poblado. Únicamente se conocen algunas de las casas excavadas en las campañas que se llevaron a cabo entre 1968 y 1970. De lo poco que se conserva en superficie y de la representación de los cortes sobre la planimetría del asentamiento, puede deducirse la organización del espacio central de la meseta en manzanas de casas, recordando otros ejemplos bien conocidos como Puente Tablas (Ruiz, 1995). Destacaremos asimismo la presencia de un contrafuerte al exterior del muro de una de las casas que permite reconstruir una segunda planta o la existencia de un espacio empedrado con cantos de río, que podría identificarse, muy probablemente, como un patio ${ }^{7}$. La fortificación del poblado, en el tramo principal de muralla, pertenece al tipo barrera. Con sus más de $10 \mathrm{~m}$ de altura, se muestra como una construcción poderosa, reconocible a una distancia considerable, emblema de la ciudad, presentando un alto valor simbólico como expresión de poder. Ofrece la falsa apariencia de una muralla en talud con bastiones y el acceso principal al poblado. También se conservan cerca del castillo otras dos puertas hasta las que se puede llegar, aún hoy, a través de caminos empedrados. El tipo de paramento de la muralla es el mismo en todos los casos: piedras pequeñas o medianas, de diferentes formas y tamaños, dispuestas formando hiladas pseudohorizontales, rellenando con otras piedras más pequeñas los huecos que van quedando. Esta fortificación completa la impresionante defensa natural del sitio, que se aprecia sobre todo desde el valle del Guadalimar $^{8}$.

7 También son frecuentes los hallazgos de molinos de piedra barquiformes, a menudo rotos, o de abundantes fragmentos de cerámica de cocina, de almacenaje o de vajilla de mesa que permiten determinar la existencia de áreas de actividad dedicadas a la producción, el almacenamiento y el consumo.

${ }^{8}$ La presentación del oppidum de Giribaile en el territorio no sería completa sin hacer mención de las perspectivas de futuro que ya se han iniciado gracias al reciente interés mostrado por el Excmo. Ayuntamiento de Vilches (Jaén) en la promoción y puesta en valor del sitio, contando con la colaboración de la Delegación Provincial de Cultura de Jaén, que viene prestando hasta el momento su inestimable ayuda y asesoramiento técnico. También el Centro Andaluz de Arqueología Ibérica ha incluido Giribaile dentro del Camino de Aníbal, una de las rutas temáticas que forma parte del Proyecto: Viaje al Tiempo de los Iberos (Ruiz et alii, 2000). De 


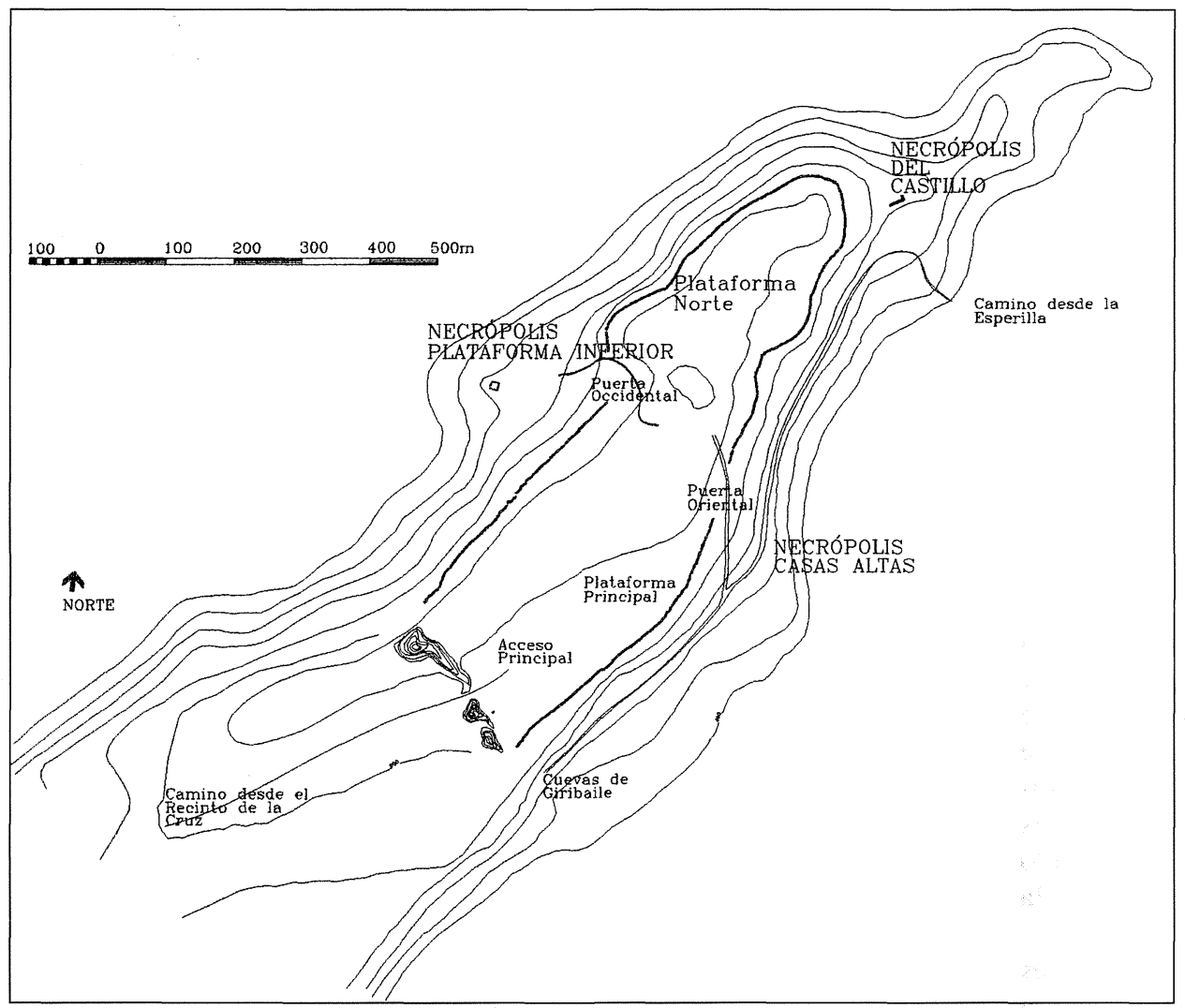

Fig. 2.-Localización de los espacios de necrópolis correspondientes al oppidum de Giribaile.

\section{EL ESPACIO FUNERARIO DE GIRIBAILE (JAÉN) ${ }^{9}$}

El espacio funerario se presenta fragmentado en tres áreas diferenciadas que rodean la privilegiada plataforma norte, adaptándose a la propia topografía del lugar y ocupando la primera curva de nivel, de condiciones favorables para los enterramientos. La denominación de los distintos espacios de la necrópolis hace referencia a su ubicación con relación a la propia meseta fortificada - la plataforma inferior-, a las ruinas del cercano castillo medieval o a las casas próximas que en la actualidad se conservan en el camino de acceso al poblado - Cortijo de las Casas Altas - (figura 2).

llevarse a cabo estas actuaciones, en los próximos años podría plantearse el inicio de un proyecto de investigación a largo plazo, centrado en Giribaile, que supere muchas de las carencias que se han puesto de manifiesto en este sitio hasta el momento.

${ }^{9}$ La mayor parte de los grandes asentamientos de la comarca, y especialmente de los oppida del curso bajo y medio del Guadalimar tales como Iliturgis, Cástulo o Giribaile, ha sufrido una actuación continuada de expoliación, preferentemente concentrada en sus necrópolis.
La plataforma inferior: el monumento funerario

El monumento funerario objeto de nuestro estudio se localiza en la necrópolis de la plataforma inferior, a la que se accede descendiendo por una pendiente no demasiado abrupta desde la puerta occidental del oppidum, a través de un camino que todavía hoy se conserva parcialmente. Tras su descubrimiento fue presentado como un edificio sacro o templo (Servajean et alii, 1986). Posteriormente fueron dados a conocer diversos elementos arquitectónicos y materiales asociados, pertenecientes al monumento (Gutiérrez, 1998b, 406, fig. 2). En la citada plataforma, de pequeñas dimensiones - no más de 0,5 ha-, que ocupa un falso rellano a media ladera, documentamos en recientes prospecciones una construcción cuadrangular de grandes bloques (figura 3), que podríamos considerar la base de un monumento funerario ibérico de grandes proporciones. Su forma y dimensiones son reconocibles parcialmente (figura 4), debido al desigual estado de conservación de los cuatro muros que delimitan su perímetro. Los bloques situados en los flancos sur y este pueden seguirse en la totalidad de su longitud 
original, no sucediendo lo mismo con los muros dispuestos en las caras norte y oeste. En cuanto al tipo de aparejo utilizado, se trata de una alineación de grandes bloques que forma a la vez la cara externa e interna del muro, pudiendo alcanzar algunos de ellos una longitud superior a $1 \mathrm{~m} \mathrm{y}$ una anchura de hasta $60 \mathrm{~cm}$. La planta de la estructura reproduce el esquema de una forma cuadrangular de aproximadamente $5 \mathrm{~m}$ de lado, del que aún se pueden identificar dos esquinas cortadas en ángulo recto, la sureste y la suroeste ${ }^{10}$.

Entre los restos del expolio destaca la importante representación de cerámicas importadas que acompañan a formas características de cerámica ibérica. El re-

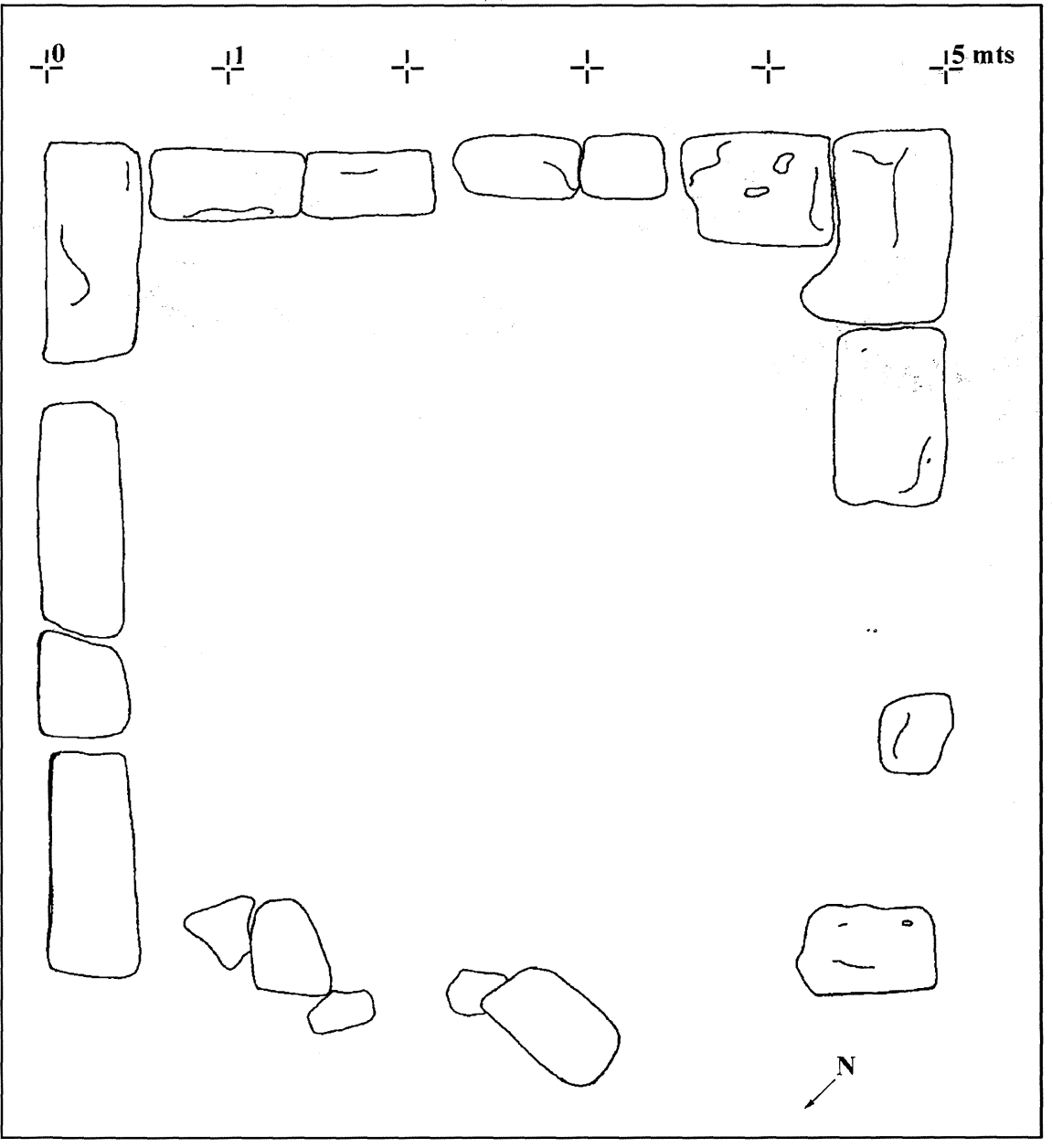

Fig. 3.-Planta del monumento funerario de la plataforma inferior de Giribaile. pertorio de vajilla áti-

ca es amplio, incluyendo crateras, copas, bolsales y, tal vez, escifos de figuras rojas, datables entre finales del siglo v y mediados del Iv a.C. ${ }^{11}$. La cronología más antigua, correspondiente a un pie posiblemente de la clase delicada y a varias crateras formando parte del ajuar que acompañaba a este

\footnotetext{
${ }^{10}$ Las dificultades de concretar otros aspectos se incrementan en el lado norte por un expolio profundo que viene a coincidir aproximadamente en el punto de unión de los muros norte y oeste. Los bloques que formaban esta esquina han sido desplazados hasta quedar diseminados por los alrededores. Además de este expolio, que avanza hacia la zona central, existe un segundo «agujero» practicado en el ángulo opuesto, el sureste, de menor tamaño y profundidad. Los hoyos efectuados por clandestinos evidencian una escasa potencia estratigráfica en el interior de la construcción, permitiendo hipotetizar que nos encontramos en realidad ante los cimientos de la misma.

$"$ Desde aquí queremos agradecer a A. Madrigal, P. Cabrera, A. Adroher y E. Sanmartí la clasificación de las cerámicas de importación procedentes del monumento funerario localizado en el sector de la necrópolis de la plataforma inferior.
}

enterramiento, confirma los resultados que proporciona el análisis de los elementos arquitectónicos del edificio, redundando en la hipótesis de que nos encontremos ante un monumento relevante, tanto por su antigüedad, que se remonta a los momentos iniciales de la ocupación de la meseta, como por el prestigio del personaje enterrado, un aristócrata local. Es significativa la presencia de materiales, en algún caso quemados, de importación $-\mathrm{y}$ de formas concretas- en el ajuar asociado al monumento. Cratera, copa de pie bajo, escifo y bolsal constituyen el servicio del vino completo en la tumba, asociado al rito de libación y al prestigio del vino en contextos funerarios. Se trata de ofrendas en honor al difunto que forman parte del rito, que en ocasiones son rotas y arrojadas a la pira, como en el conocido conjunto de Pozo Moro con copa, jarra y frasco de perfumes o en Los Villares (Olmos et alii, 1999). 


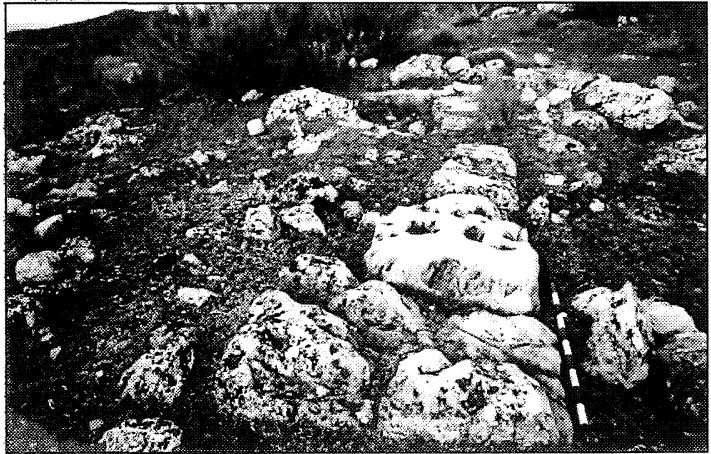

Fig. 4.-Restos del monumento funerario de la necrópolis de la plataforma inferior de Giribaile.

Tras nuestro reconocimiento del lugar, fue documentada in situ una serie de bloques pétreos junto a la estructura cuadrangular conservada, en un radio de escasos metros, alguno de los cuales ya ha sido presentado (cf. supra). Estos materiales se hallan fragmentados y deteriorados, siendo un conjunto incompleto. La piedra empleada, el asperón, es una arenisca tierna local, de color blanquecino-amarillento, de textura blanda, poco compacta ${ }^{12}$. El escultor ibérico recurre a las calizas y areniscas del entorno, generalmente de fácil labra, como las de este yacimiento $\mathrm{y}$, consecuentemente, de rápido deterioro. Presentamos, a continuación, el catálogo de elementos, en cuya selección ha primado la existencia de algún indicio de labra, huellas de trabajado o mortajas en el bloque.

- Sillar de gola 1 (figura 5; Servajean et alii, 1986, 46; Gutiérrez, 1998b, 406): bloque arquitectónico fragmentado dẹ un sillar de esquina con moldura de gola, de filete y nacela lisos. Presenta una fractura importante y un elevado grado de alteración, como en el resto de elementos. Sus dimensiones generales máximas (altura $\times$ anchura $\times$ profundidad) son de $46 \times 119 \times 66 \mathrm{~cm}$, siendo la altura del filete de $11 \mathrm{~cm}$ y el vuelo de la nacela de $35 \mathrm{~cm}$. No permite apreciar baquetón, que en ocasiones com-

${ }^{12}$ Según el estudio de B. Ceprián del Castillo (Acercamiento a la determinación de las fuentes de materia prima de los componentes líticos del monumento funerario de Giribaile), a quien agradecemos su colaboración, se han distinguido distintos tipos de rocas: areniscas de color amarillento con granulometría poco clasificada y algún pequeño fósil lamelibranquio, propias de los afloramientos de la zona; calizas de color grisáceo, masivas y compactas, procedentes del afloramiento del extremo más occidental de la Sierra de Cazorla, utilizadas igualmente en la muralla ibérica; así como pequeños cantos rodados de pizarras oscuras y cuarcitas blanquecinas, cuyo origen está determinado por la erosión y el arrastre fluvial, documentándose al pie del asentamiento, debido sobre todo al aporte del río Guadalén y sus afluentes, depósitos cuaternarios con estos materiales.



Fig. 5.-Sillar de gola 1 de Giribaile. Bloque arquitectónico de esquina con función de cornisa.

plementa este tipo arquitectónico en otros monumentos funerarios ibéricos, ni otras molduras o la labra de relieve alguno. La pieza presenta una fractura longitudinal central desde el extremo del filete que afecta a gran parte del bloque. La parte superior del bloque, desbastada y especialmente alterada, documenta parte de dos mortajas de grapa, una en forma conocida como «cola de milano» de $10 \mathrm{~cm}$ de longitud $\times 6 \mathrm{~cm}$ de profundidad y $9 \mathrm{~cm}$ de anchura en el brazo conservado. La forma de la segunda mortaja de grapa apenas puede definirse, siendo tal vez en forma de «Y». Su longitud es de $16 \mathrm{~cm}$ y la anchura del brazo, mal definida, es de, al menos 7 $\mathrm{cm}$. Su profundidad es de $1 \mathrm{~cm}$.

- Sillar de gola 2: bloque arquitectónico fragmentado liso, perteneciente probablemente al mismo elemento de coronomiento anterior. Sus dimensiones generales máximas son de $35 \times 70 \times 61 \mathrm{~cm}$.

- Sillar de gola 3: bloque arquitectónico fragmentado, perteneciente probablemente al mismo elemento de coronomiento anterior. Sus dimensiones generales máximas son de $38 \times 47 \times 38 \mathrm{~cm}$. En su cara inferior la piedra se ha recortado siguiendo una línea curva que recuerda la forma característica de una «cola de milano». El considerable tamaño de la mortaja, que oscila entre 19 y $30 \mathrm{~cm}$ de anchura y el hecho de que este rebaje no presente indicios de 
haber contenido en su interior metal fundido, nos induce a pensar que el elemento de ensamblaje utilizado en este caso fuera de madera.

- Sillar de gola 4: bloque arquitectónico fragmentado, perteneciente probablemente al mismo elemento de coronamiento anterior. Sus dimensiones generales máximas son de $31 \times 113 \times 81$ $\mathrm{cm}$.

- Sillar 5: gran bloque arquitectónico fragmentado, liso, cuadrangular. Sus dimensiones generales máximas son de $38 \times 93 \times 67 \mathrm{~cm}$. No se observa ningún tipo de moldura complementaria, quedando la incógnita de su pertenencia al sillar de gola al que corresponden los anteriores fragmentos.

- Sillar 6: bloque arquitectónico fragmentado, liso, cuadrangular. Sus dimensiones generales máximas son de 22 $\times 40 \times 28 \mathrm{~cm}$. Presenta en una de sus caras una mortaja de grapa en forma de

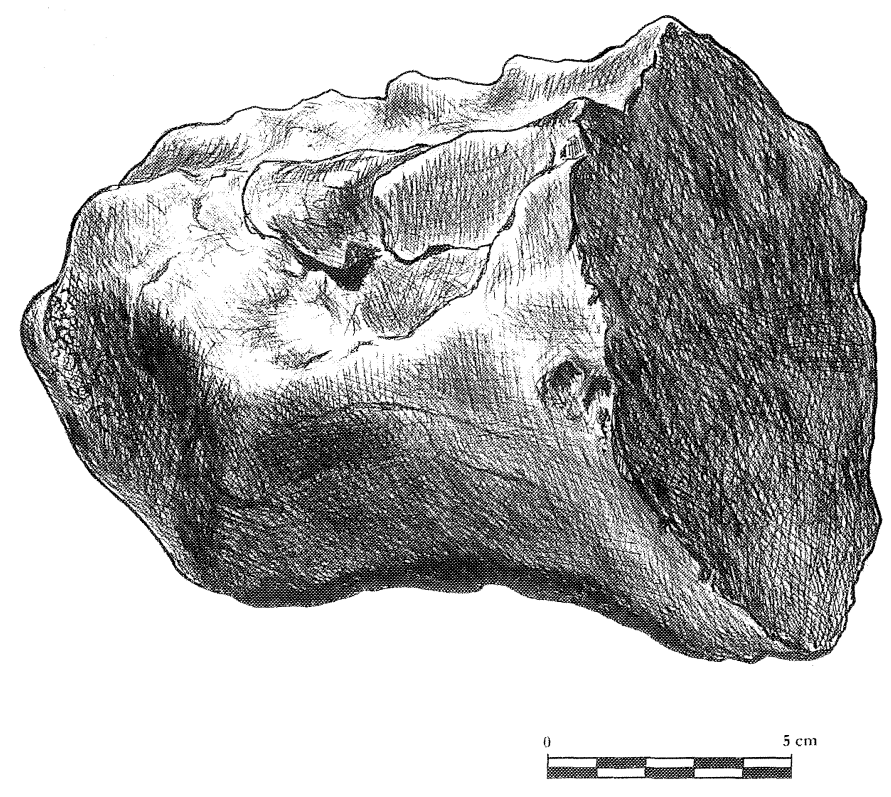

Fig. 6.--Elemento escultórico fragmentado de la plataforma inferior de Giribaile.
«T» cuyos brazos tienen unas dimensiones de 9 y 8 $\mathrm{cm}$ de longitud $\times 1,5 \mathrm{~cm}$ de anchura; conserva parte de la lámina de plomo de la propia grapa in situ.

- Sillar 7: bloque arquitectónico fragmentado, liso, cuadrangular. Sus dimensiones generales máximas son de $30 \times 38 \times 26 \mathrm{~cm}$. En una de sus caras presenta huellas de trabajado que indican la utilización de un cincel de boca recta de $1,5 \mathrm{~cm}$ de anchura.

- Sillar 8: bloque arquitectónico fragmentado, liso, cuadrangular. Sus dimensiones generales máximas son de $14 \times 30 \times 26 \mathrm{~cm}$. Presenta igualmente en una de sus caras huellas de trabajado de un cincel de boca recta de $1,5 \mathrm{~cm}$ de anchura.

- Escultura indeterminada (figura 6): fragmento escultórico muy rodado cuyas dimensiones generales máximas son de $15 \times 12,5 \mathrm{~cm}$. Tan sólo puede reconocerse lo que hipotéticamente hemos interpretado como la talla de una crin y la curvatura del cuello de un équido, que podría evocar la escultura aparecida en el enterramiento XIX de la necrópolis del Estacar de Robarinas (García-Gelabert y Blázquez, 1988, 54-55, lám. XXIII-XXV). Desconocemos si se trata de una escultura exenta o de un elemento escultórico con función arquitectónica; la parte posterior de la pieza presenta una superficie regularizada y plana que, aparentemente, había sido preparada para adosarse a un edificio, pudiendo tratarse tal vez de un fragmento muy deteriorado de un sillar de esquina zoomorfo.

Se trata de un conjunto reducido, formado por sillares lisos, pertenecientes al alzado y al corona- miento de la estructura, ensamblados mediante grapas metálicas ${ }^{13} \mathrm{y}$, eventualmente, de madera. La construcción se remata con una esbelta cornisa con moldura de gola, totalmente lisa. Queda planteada la incógnita de la situación del fragmento escultórico en este monumento, al modo de un altorrelieve, o en otra tumba monumental. Sin duda el elemento más interesante es la cornisa con moldura de gola. La utilización de este tipo de piezas en la arquitectura ibérica nos sitúa ante un edificio funerario, según sus contextos de hallazgo (Almagro-Gorbea, 1983; Castelo, 1995; Izquierdo, 2000). Los ejemplos conocidos de, fundamentalmente, pilares-estela con golas lisas - Los Capuchinos (Caudete, Albacete), Corral de Saus (Mogente, Valencia), Baza (Granada), Los Nietos (Murcia)- o monumentos en forma de torre - Pozo Moro (Chinchilla, Albacete) - así lo evidencian. La altura total de la gola de Giribaile es menor que las dos de Pozo Moro, con 52 y $53 \mathrm{~cm}$ respectivamente (Almagro-Gorbea, 1983, 206), aunque superior a la esquina de gola con nacela lisa del monumento de Los Nietos (Murcia) que tiene una altura máxima de $15 \mathrm{~cm}$ (Cruz, 1990, 206-207). Se sitúa, pues, en una posición intermedia entre las golas con nacelas lisas muy altas

\footnotetext{
3 Según el estudio de F. A. Corpas Iglesias del Dpto. de Ingenierías Química, Metalúrgica y de los Materiales de la Universidad de Jaén (Estudio metalográfico.Caracterización microestructural), a quien agradecemos su colaboración, las grapas asociadas al monumento de Giribaile están fabricadas
} en plomo. 


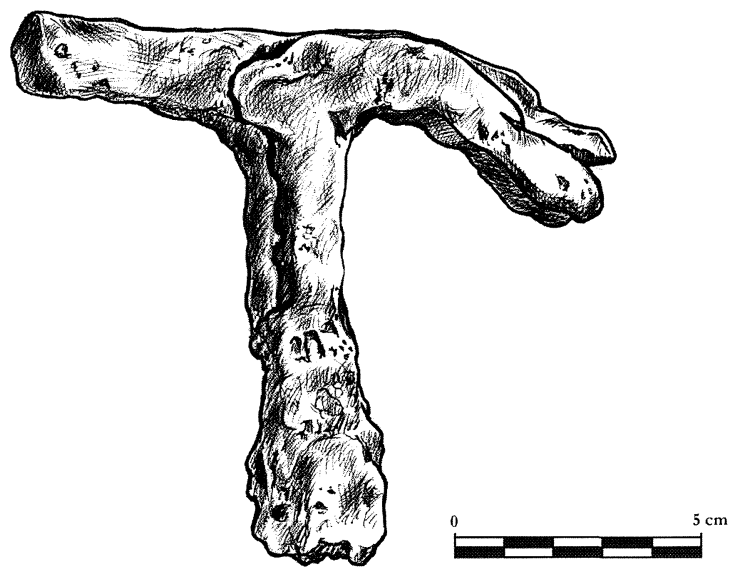

Fig. 7.-Grapa en forma de "T" de Giribaile.

y poco curvadas tipo Pozo Moro y las más pronunciadas, con un vuelo mayor, de los pilares-estela como el de Los Nietos. Si tomamos en consideración otros elementos del sillar de gola de Giribaile, el filete liso, de $11 \mathrm{~cm}$ de altura, se aleja de los 4,5, 5,5 y $6,5 \mathrm{~cm}$ de los pilares-estela de Corral de Saus (Mogente, Valencia), Los Capuchinos (Caudete, Albacete) o Coy (Monforte del Cid, Alicante), acercándose a los $13,2 \mathrm{~cm}$ - cerca de 2 palmos- del gran pilar-estela de Arenero del Vinalopó (Monforte del Cid, Alicante). Con respecto al vuelo de su nacela, la gola de Giribaile supera los 4 palmos o 1 pie $^{14}(28 \mathrm{~cm})$ del capitel del citado pilar-estela de

${ }^{14}$ Estamos, no obstante, tanteando un tema complejo, que para el caso de Iberia nos sitúa en un terreno resbaladizo: el del posible análisis metrológico en la arquitectura funeraria ibérica (Izquierdo, 2000). El reconocimiento de unidades métricas implica el establecimiento de una arquitectura modulada de alcance general, es decir, de una pauta reconocida como modelo por el órgano rector de la sociedad. Las propuestas en cuanto a patrones proporcionales, modulares o metrológicos en contextos funerarios fueron explicitados por Almagro-Gorbea (1092, 1983). Así, al capitel del pilar-estela de Coy (Murcia) se le ha atribuido la correspondencia con un pie teórico de unos $28 \mathrm{~cm}$; en Pozo Moro, se ha propuesto la existencia de una unidad de medida o pie teórico de 30 $\mathrm{cm}$ y un codo teórico de $45,6 \mathrm{~cm}$, a partir de la dimensión de la base del monumento; en todo caso, se plantea el seguimiento de una base duodecimal, de origen oriental (Almagro-Gorbea, 1983, 211-212, n.p.p. 175 y 176). Los monumentos de Alcoy o Monforte del Cid (Almagro Gorbea, 1982, 175; Almagro y Ramos, 1986, 22) cuentan asimismo con propuestas metrológicas, fundamentalmente, a partir del estudio del capitel. Por otra parte, el análisis de conjunto llevado a cabo en los monumentos funerarios del tipo pilar-estela (Izquierdo, 1998) indica que los cálculos obtenidos no implican tendencias rotundas. En las dimensiones entre los distintos elementos de los capiteles, por ejemplo, se han reconocido relaciones esencialmente aritméticas. Más que de pautas metrológicas estrictas, se observa la repetición de ciertas unidades de medida. Esto es propio de la institucionalización del oficio de construir monumentos. Fi-

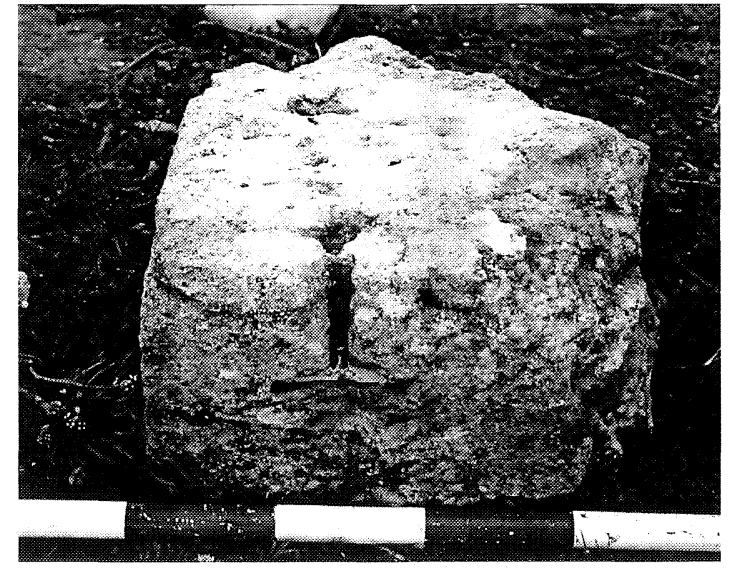

Fig. 8.- Sillar 6 con mortaja de grapa de Giribaile.

Arenero del Vinalopó. Estamos, por tanto, ante una pieza de coronamiento que se aproxima en sus formas y proporciones a los capiteles con molduras cóncavas, en general esbeltas, de los pilares-estela, aunque de dimensiones mucho mayores. La gola remataría, pues, una estructura de altura considerable teniendo en cuenta, además, la superficie de la base del monumento ( $c f$. infra).

En las inmediaciones del edificio hemos documentado sillares bien escuadrados, con marcas visibles de talla. La uniformidad y regularidad de las medidas de los bloques 6,7 y 8 del catálogo -en algún caso con huellas de trabajado-, especialmente por lo que se refiere a la altura, comprendida entre 26 y $28 \mathrm{~cm}$, permite plantear la hipótesis de que se tratara de elementos pertenecientes al alzado del edificio, formando parte tal vez de las gradas escalonadas sobre las que debió levantarse el monumento funerario. Por otra parte, los sistemas de ensamblaje entre bloques mediante grapas metálicas de plomo quedan documentados en Giribaile a través de una mortaja, en el sillar 6, y una grapa en forma de «T» (figuras 7 y 8 ) -recogida esta última entre los despojos del expolio del monumento, siendo sus dimensiones de $9 \times 10,2 \mathrm{~cm}$ y $1,7 \mathrm{~cm}$ de anchura-; dos mortajas de grapa en forma de «cola de milano», una en el sillar de gola 1 y otra en el sillar de gola 3 , siendo esta última de grandes dimensiones; además de una mortaja dudosa (sillar de gola 1) y una grapa de plomo en forma de «Y» (figura 9), esta última descubierta en la necrópolis del Castillo.

nalmente, otro hecho a observar es que, aunque la consecuencia del derrumbe de los monumentos ibéricos no está directamente motivada por la ausencia de una pauta canónica, sí es cierto que un cálculo metrológico sirve para que los constructores obtengan una fórmula adecuada a la estabilidad de una obra. 


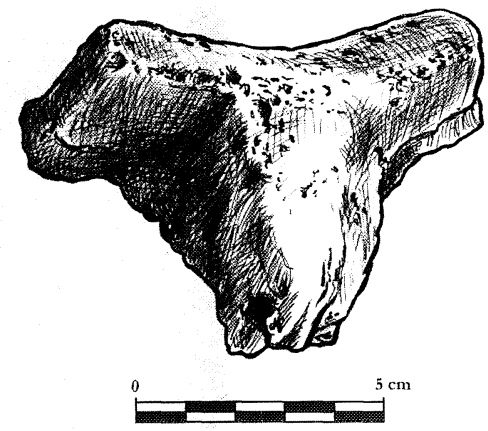

Fig. 9.-Grapa en forma de "Y" de Giribaile".

Estos testimonios de grapas metálicas ${ }^{15}$ se documentan por vez primera en monumentos del Alto Guadalquivir, ya que hasta el momento tan sólo había sido reconocida en una pieza escultórica, el toro de Arjona (Almagro-Gorbea y Rubio, 1980, 350352).

Finalmente, hemos de valorar la presencia, junto al monumento, de un pequeño pavimento de guijarros $(20 \times 15 \mathrm{~cm})$ que aún hoy se conserva en parte. El desprendimiento del sillar de gola hacia el exterior del edificio y el hecho de haberse mantenido en el mismo lugar durante siglos ha preservado parcialmente el mosaico. Este pavimento sería posiblemente mucho más extenso. Forma un motivo en espiga compuesto en su alineación inferior por 7 guijarros alargados planos de color gris oscuro con disposición subparalela y tan sólo 1 dispuesto en sentido contrario, dando la réplica en la alineación superior y completando el motivo decorativo ${ }^{16}$. Este tipo de guijarros, con características similares en cuanto a

${ }^{15}$ Las grapas en forma de «T» son bien conocidas en los repertorios de arquitectura funeraria ibérica. Los ejemplos de Giribaile están próximos en sus dimensiones a los hallados en el monumento funerario de Horta Major de Alcoy $(14 \times 6$ y $170 \times 7,5 \mathrm{~cm}$ de longitud de brazos) o las recuperadas en La Alcudia $(15 \times 7 \mathrm{~cm})$ (Almagro-Gorbea, 1982, 165-168). En los monumentos las grapas constituyen elementos clave en el sistema de anclaje de bloques. De los distintos tipos documentados, las formas en «T» son las más abundantes - 17 en total, en el Cerro de los Santos (Montealegre del Castillo), Llano de la Consolación, El Lobo, El Cigarralejo (Mula), La Alcudia (Elche), Horta Major (Alcoy), Pino Hermoso, Los Villares (Hoya Gonzalo) y Corral de Saus (Mogente)-, seguidas de las grapas de "cola de milano» - 8 en total, en Pozo Moro (Chinchilla), El Prado (Jumilla), La Alcudia de Elche, Los Capuchinos (Caudete) y más imprecisamente en Corral de Saus-, frente a las en forma de «Y» -5 en total, en El Cigarralejo, Los Nietos, Llano de la Consolación o Corral de Saus-.

${ }^{16}$ Asimismo es posible reconocer una caótica dispersión de guijarros en el flanco sur del edificio, resultado de una destrucción reciente del pavimento, que hipotéticamente podríamos relacionar con la desaparición de algunas de las cornisas y capiteles cuya existencia conocemos a través de las fotografías de la publicación de Servajean et alii (1986).

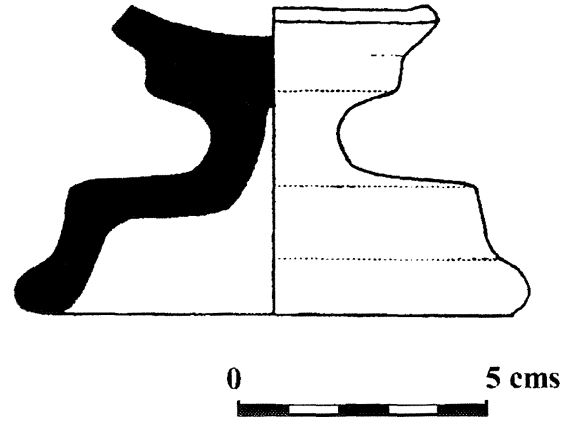

Fig. 10.-Necrópolis del Castillo de Giribaile. Ajuar funerario: fragmento de imitación de cratera.

forma y color, han podido ser identificados en el sector de la necrópolis junto al Castillo, así como en el oppidum. La presencia de un pavimento que a modo de greca o cenefa rodea el edificio, es un aspecto cualitativamente importante a la hora de valorar una construcción funeraria, especialmente cuando estamos ante un monumento en el que se concentra un elevado costo, en términos de inversión de trabajo, por parte de la comunidad. En opinión de Blázquez y García-Gelabert (1987), la presencia de estos mosaicos en Cástulo es prácticamente continua desde el siglo vil hasta mediados del IV a.C., siendo utilizados como pavimentos en el «santuario» de Baños de la Muela. Se han identificado motivos de grecas que rodeaban los grandes monumentos funerarios ${ }^{17}$, incluso a veces pequeños enterramientos tumulares, como en Estacar de Robarinas o los Higuerones.

\section{Necrópolis de la ladera del castillo}

Esta necrópolis, que ha sufrido asimismo un intenso saqueo, con una extensión de entre 0,5 y 1 ha aproximadamente, ocupa una pequeña elevación situada bajo el escarpe septentrional del farallón rocoso donde se alza el oppidum, en las proximidades del castillo, a poca distancia de la necrópolis de las Casas Altas, quedando separadas por una profunda vaguada. Entre ambas se establece comunicación visual y un camino de acceso desde el valle, seguramente desde algún punto de la Esperilla, que ascendía por la ladera hasta alcanzar la puerta orien-

17 Estos mosaicos también pudieron cumplir una función similar al pasillo lateral que rodeaba la sepultura 11/145 de los Castellones de Ceal (Hinojares, Jaén), formando una zona de paso con un suelo de tierra apisonada y guijarrillos sueltos, revestido de yeso pintado de rojo (Chapa et alii, 1998). La sepultura de los Castellones como la de Giribaile se fecha en la primera mitad del siglo IV a.C. con la amortización de piezas áticas de fines del $v$ a.C. 


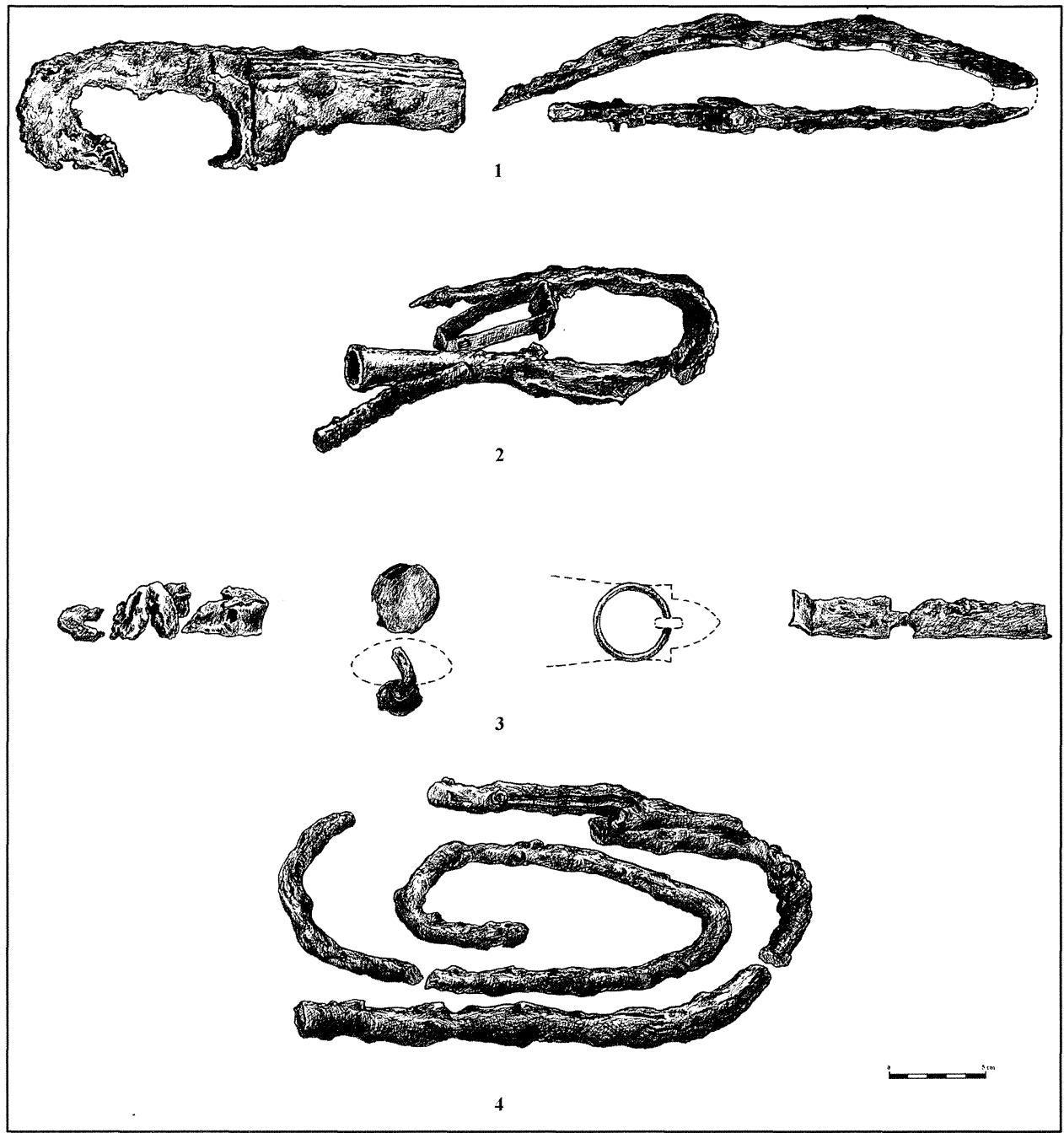

Fig. 11.-Necrópolis del Castillo de Giribaile. Ajuar funerario: panoplia.

tal del oppidum. En el perfil de uno de los hoyos, consecuencia de la expoliación, fue detectado parte del ajuar de una tumba. En la parte superior se halló un vaso fragmentado, tal vez la urna cineraria, correspondiente a un pie alto de base moldurada en cerámica clara, con un engobe rojo (figura 10), que puede incluirse en el grupo 9 de Pereira de «imitaciones» de vasos áticos (Pereira, 1989, 154-155). Los paralelos ${ }^{18}$ nos permiten situar la cronología de esta tumba en el siglo iv a.C. Bajo este vaso se dis-

18 Formalmente presenta una gran semejanza con una pieza procedente de la necrópolis de Toya (Peal de Becerro, Jaén), variante $9 \mathrm{~B}-\mathrm{I}$, que reproduce los elementos y proporciones de una cratera de campana del siglo iv a.C. Estos pies altos y moldurados también los encontramos en el tipo 9-C, representados por los ejemplares de Toya y Giribaile, semejantes a una cajita, procedente de la necrópolis de Baza (Aranegui, 1992, lám. III). ponía la panoplia (figura 11), formada por una falcata con empuñadura en forma de cabeza de caba1lo, una punta de lanza, un soliferreum y diversos fragmentos de un escudo. Estas armas habían sido destruidas, doblándolas intencional y ritualmente, antes de proceder a su enterramiento, hecho éste que unido a la acción del fuego y a la colocación de unas piezas sobre otras ha provocado que muchos fragmentos se hayan fundido entre sí. Mezclados con la tierra aparecieron, finalmente, restos de cenizas y huesos quemados, correspondientes a la cremación y una ofrenda de la que formarían parte dos tabas. No fue posible identificar la estructura de la tumba, aunque la presencia de algunas piedras planas de pequeño tamaño en los alrededores nos lleva a pensar en una pequeña cista o estructura pétrea sencilla, o, simplemente para entibar la urna. 
Los numerosos expolios que hemos observado en este montículo, en general, han puesto al descubierto los negativos de las sepulturas, quedando en superficie evidencias de los alzados de algunos enterramientos. Sus formas son cuadrangulares o rectangulares y debieron contener en su interior las urnas cinerarias y los ajuares, pudiendo disponerse éstos en simples fosas delimitadas por piedras ${ }^{19}$. En las inmediaciones de un muro ciclópeo documentado en este espacio funerario, se distinguen por ejemplo dos estructuras, relativamente bien conservadas, de $1,5 \times 1,2 \mathrm{~m}$

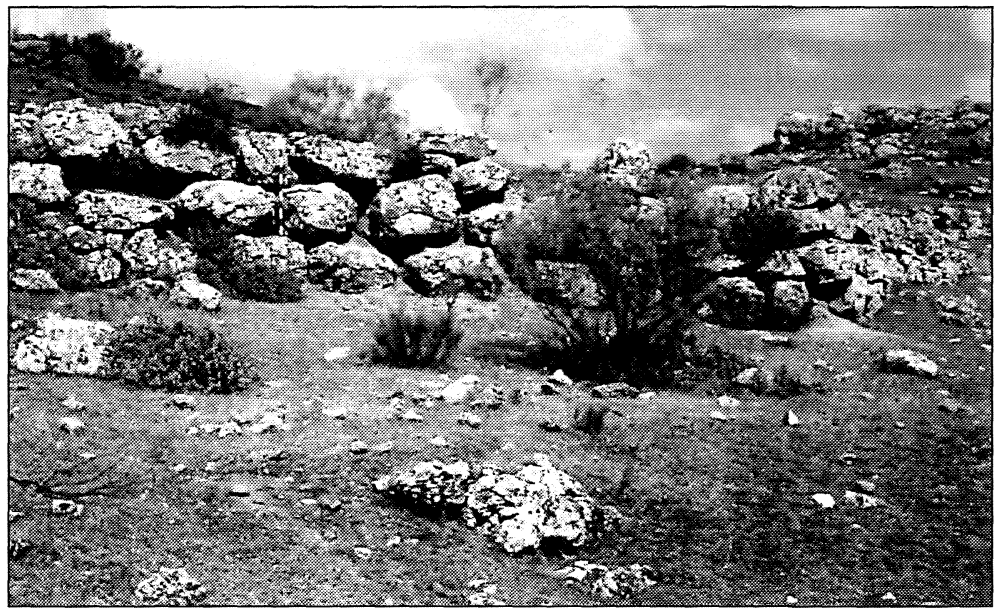

Fig. 12.-Muro ciclópeo de Giribaile. y $1 \times 1 \mathrm{~m}$. Asimismo, al pie de la ladera del Casti1lo, se identifican en superficie alineaciones de piedras que dan forma a dos sepulturas cuadrangulares paralelas dispuestas a distinta altura de 2,5 × 2,4 m de lado aproximadamente. Sus muros están formados por bloques de dimensiones medias de aproximadamente $30 \times 25 \mathrm{~cm}$. Del resto de tumbas, muy mal conservadas, sólo conocemos su presencia por las huellas de los expolios. El citado muro ciclópeo (figura 12; Servajean et alii, 1986, 45) parece dividido en dos lienzos. El de mayor longitud sigue una orientación suroeste-nordeste a lo largo de cerca de $10 \mathrm{~m}$, para girar aproximadamente $30^{\circ}$ en dirección noroeste en un corto tramo de unos $2 \mathrm{~m}$. Está construido con grandes bloques de piedra apenas trabajados dispuestos en seco, de tosca apariencia. Presentan caras poco desbastadas, de superficies más o menos aplanadas y regularizadas, que mantienen una cierta alineación. Se observa una cierta regularidad en las dimensiones de los bloques, variando su longitud máxima entre 0,5 y $2 \mathrm{~m}$. La altura máxima del lienzo es de $1,8 \mathrm{~m}$, resultado

19 Pese a que la concentración de trabajos ilegales es máxima sobre la cima del cerro, por debajo de dicho montículo, nuevos expolios parecen confirmar la continuidad del espacio funerario. Entraña grandes dificultades intentar establecer una tipología de los posibles enterramientos presentes en esta necrópolis. En la mayor parte de los casos tan sólo se puede asociar la presencia de bloques de piedra de gran tamaño, cuya longitud máxima puede oscilar entre los $80 \mathrm{~cm}$ y $1,5 \mathrm{~m}$, a huellas de expolios, creando un paisaje funerario característico formado por la alternancia de estas grandes piedras colocadas in situ con la presencia de montones de tierra removidos. En algunos casos pueden identificarse enterramientos cuya estructura es de tendencia rectangular o cuadrangular. Parece tratarse de los característicos empedrados o estructuras tumulares sencillas, de dimensiones que no exceden en ningún caso $\operatorname{los} 2,5 \mathrm{~m}$ de lado. de la superposición de tres hiladas. Por el tipo de aparejo recuerda a otras construcciones de similares características distribuidas en diferentes puntos de la provincia de Jaén, como la muralla de Ibros o Cerro Miguelico (Molinos, 1997a, 1269 y 1997b, 2455). En ambos casos la cronología propuesta se sitúa entre finales del siglo I a.C. y la primera mitad del i d.C. Su disposición representa el límite de los expolios reconocibles sobre esta plataforma (figura 13) e hipotéticamente permite considerarla como un temenos o límite del espacio funerario ${ }^{20}$ en torno al cambio de Era.

\section{Necrópolis del cortijo de las Casas Altas}

Este espacio funerario ocupa algo más de 1 ha y se sitúa al pie del flanco sureste del farallón rocoso de la meseta, en el primer rellano que forman las curvas de nivel bajo el escarpe. Con respecto a los materiales recuperados, orientan un periodo entre el 450 y 400 , perdurando en uso con seguridad al menos hasta el 300 a.C. Se trata de formas áticas abiertas, posiblemente páteras o cílicas. Las

${ }^{20}$ Del mismo modo, en un momento anterior y cumpliendo una función parecida, podríamos mencionar el muro de la necrópolis de Castellones de Ceal (Chapa y Pereira, 1992, 436), no exento del «efecto ciclópeo» o de monumentalidad destinado a crear un impacto visual. Otros muros pétreos aunque también podrían ser de adobe-, de dimensiones mucho menores, son conocidos en las necrópolis ibéricas del Ibérico pleno y tardío. Se trata de un tipo de señalización documentada desde cronologías antiguas, mantenida hasta época romana. Algunos ejemplos pueden observarse en la necrópolis de Pozo Moro, el citado caso de Castellones de Ceal, La Torrecica del Llano de la Consolación, El Tolmo de Minateda, Corral de Saus e hipotéticamente en Hoya de Santa Ana. 


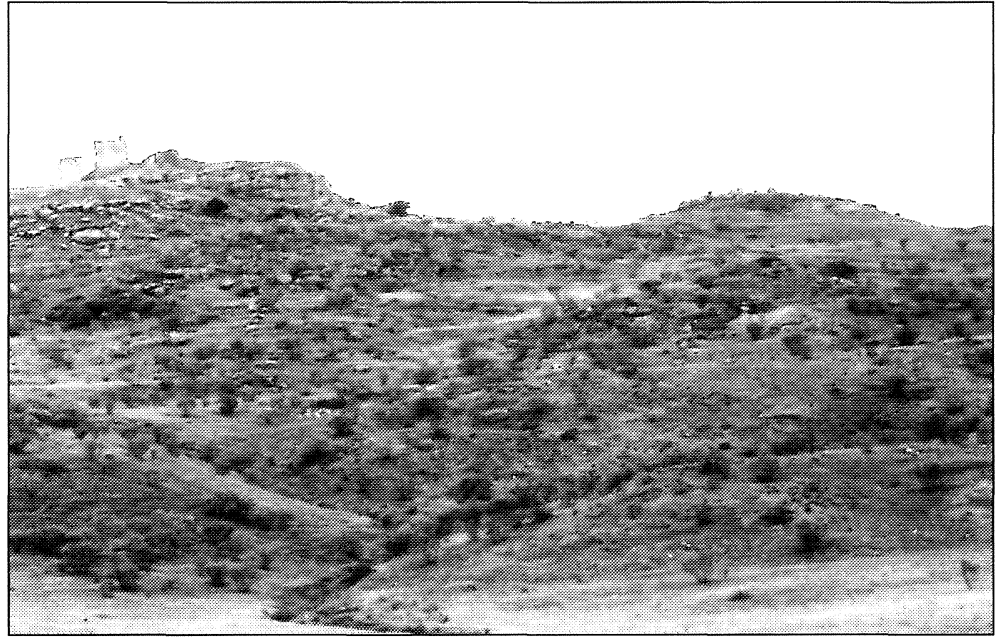

Fig. 13.-Necrópolis del Castillo de Giribaile.

huella de actividades rituales desarrolladas en el área funeraria con presencia de fuego, así como líquidos y/o perfume. Y su consecuencia en el registro podrían ser manchas de ceniza ${ }^{23}$. Finalmente contamos con referencias orales sobre la presencia en la necrópolis de algún tipo de escultura, ciertas «cabezas de carnero», que pudieron formar parte de alguna tumba con superestructura escultórica. Al parecer estos fragmentos de esculturas de gran tamaño permanecieron diseminados en superficie durante largo tiempo, hasta que finalmente fueron expoliados. La existencia y la disposi-

dos piezas que proporcionan una mayor precisión cronológica son un fragmento decorado con un motivo central de palmetas, posterior al 375 a.C., y una copa Cástulo de muy mala calidad, que aporta una cronología ${ }^{21}$ en torno al 400 a.C. Más allá de la pequeña superficie aterrazada donde afloran restos de tumbas descubiertas a lo largo de años de expoliación, sus límites sur y este son difíciles de precisar, ya que ladera abajo sus vestigios se confunden con los abundantes materiales de arrastre, haciendo muy compleja la separación de conjuntos cerámicos por horizontes culturales. Se reconocen manchas de cal que probablemente puedan relacionarse con la ubicación de algunas sepulturas ${ }^{22}$. En la parte superior de la necrópolis se documenta una mancha de ceniza de más de $1 \mathrm{~m}$ de diámetro que recuerda por su forma y dimensiones a las fosas ovaladas de Castellones de Ceal (Pereira y Madrigal, 1994, 385). Otra posibilidad que no podemos descartar es que esta fosa de forma ovalada con cenizas pueda interpretarse como ustrina o una

21 Recordemos cómo en Cástulo confluían en estos momentos dos vías de circulación de productos áticos, que quedaban en manos de intermediarios púnicos (Olmos, 1988), aunque funcional e iconográficamente son los iberos los encargados, posiblemente, de seleccionar el tipo de piezas importadas (Chapa et alii, 1993, 416-417).

${ }_{22}$ Una de estas manchas tiene unas dimensiones aproximadas de $0,8 \times 0,9 \mathrm{~m}$, siendo por su forma prácticamente cuadrada. La segunda, también de forma cuadrangular, es de $0,8 \times 0,75 \mathrm{~m}$. Podrían interpretarse como tumbas destruidas por el paso de la maquinaria agrícola y corresponderían a enterramientos ibéricos documentados en otros puntos de la provincia: cistas o empedrados de planta cuadrada o rectangular sobre los que se levanta un alzado de losetas de adobe que suelen ir revestidos de una lechada de cal, tal como se describen en las excavaciones de Castellones (Chapa y Pereira, 1992, 437). ción de estas esculturas en la necrópolis son hoy una incógnita.

\section{EL ESPACIO FUNERARIO DE GIRIBAI- LE EN EL MARCO DEL SURESTE PENIN- SULAR}

El estudio del espacio funerario del oppidum de Giribaile, conocido básicamente mediante prospección, presenta un triple interés, a pesar de las expoliaciones, el estado de conservación de las estructuras y la fragmentación de los materiales: sus dimensiones y disposición; su relación y comunicación con el hábitat y los tipos de tumba documentados, entre los que se destaca la presencia de un monumento funerario de grandes dimensiones. Se ha de señalar inicialmente la disposición fragmentada, adaptada naturalmente alrededor del gran asentamiento, de un área fortificada, de grandes dimensiones, con una extensión de varias hectáreas. Se establece, además, una relación visual entre los distintos sectores de necrópolis y una comunicación directa con los accesos a la ciudad. Los espacios funerarios pueden ser contemplados, de esta forma, según la tradición ibérica, en el camino de entrada, a las puertas de la meseta fortificada. Con relación a los tipos de tumba, empedrados tumulares más o menos sen-

${ }^{23}$ Así, el área sacra de «Las Agualejas» en la orilla izquierda del Vinalopó (Alicante) ha proporcionado algunas claves de análisis al ofrecer la imagen de un conjunto de estructuras, posibles depósitos o desechos rituales relacionados con tumbas próximas, de los siglos $v$ al 1 a.C., que debieron formar parte de la necrópolis de la que proceden el conocido pilar-estela y la escultura de toro de Monforte del Cid (Abad, Sala y Alberola, en prensa). 


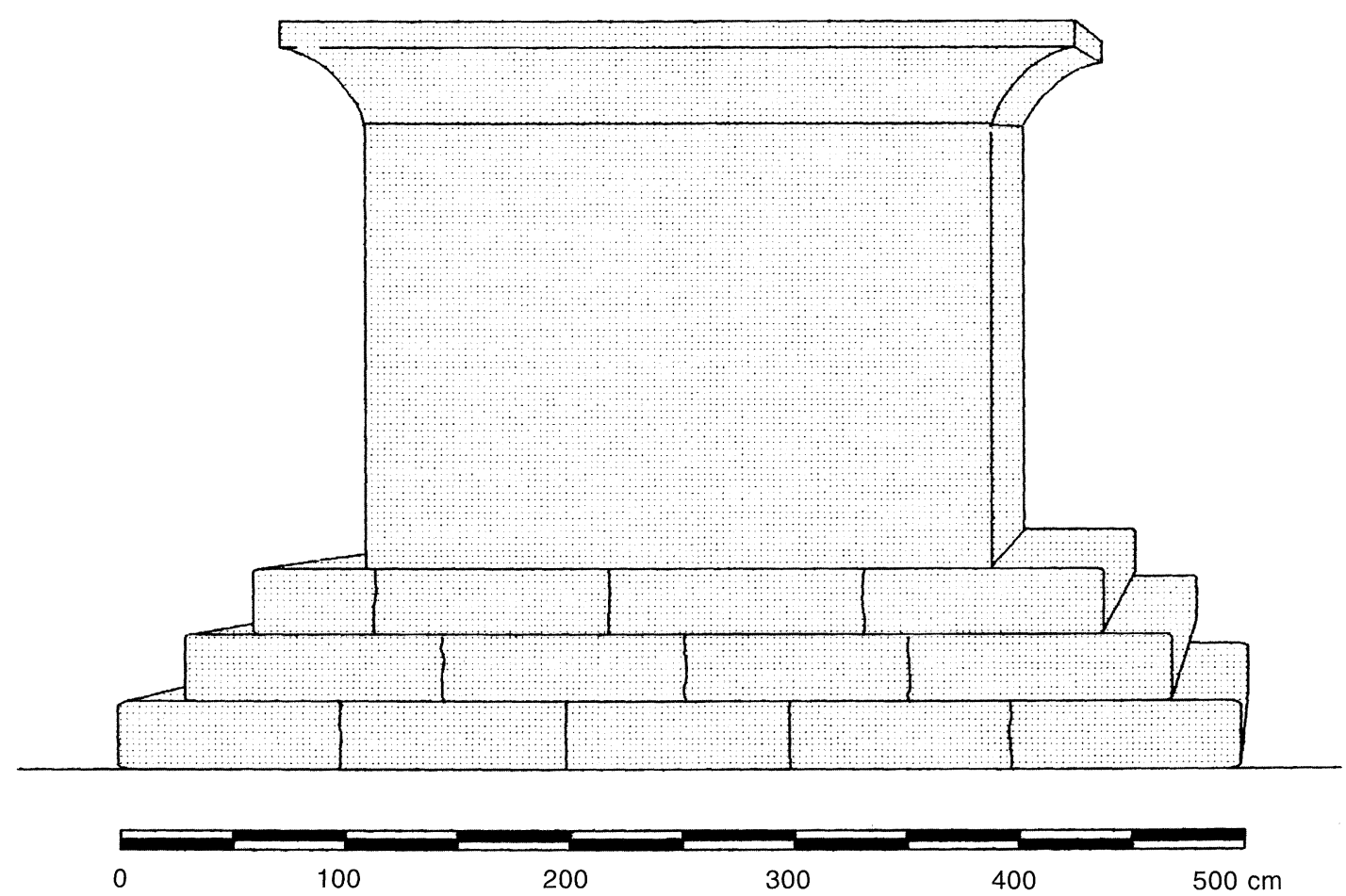

Fig. 14.-Propuesta de restitución del monumento funerario de la necrópolis de la plataforma inferior de Giribaile.

cillos, de forma cuadrangular o rectangular, fosas, cistas o cajas, entre otros, parecen haber sido empleados en Giribaile como lugares de enterramiento. Es lógico, por otra parte, que se evidencie una tipología plural en las tumbas y muy distintos grados de monumentalidad, dadas las grandes dimensiones del hábitat.

$\mathrm{Al}$ monumento de la plataforma inferior se accede desde la puerta occidental del oppidum. No parece haber sido la única construcción monumental dotada, tal vez, de esculturas en Giribaile, ya que existen testimonios sobre la existencia, de piezas escultóricas zoomorfas, hoy perdidas, en la necrópolis del Cortijo de las Casas Altas. Una valoración global de esta construcción, permite establecer la hipótesis de que nos encontramos ante un monumento aristocrático, que podría valorarse en un proceso de anastylosis, similar al de Pozo Moro (Almagro-Gorbea, 1983) y otros monumentos funerarios, fundamental, aunque no exclusivamente, del tipo pilar-estela (AlmagroGorbea, 1983; Blánquez y Antona, 1992; Aranegui et alii, 1993; Castelo, 1995; Izquierdo, 2000). No estamos en Giribaile ante la presencia de un pilar-estela, sino ante un monumento ${ }^{24}$ de una envergadura ma-

${ }^{24}$ En general, ante el estado de conservación, el alto grado de destrucción de los monumentos funerarios ibéricos, y yor, según indica el perímetro de su base y las dimensiones de la gola, equiparables a las plataformas definidas en Cabezo Lucero (Aranegui et alii, 1993). Si bien el nivel de destrucción se presenta en un estado avanzado, aún puede intentarse una aproximación al volumen y la forma del monumento gracias a la presencia de diversos fragmentos de cornisa de gola de grandes dimensiones, de diversos bloques de cantería y de varios tipos de grapas de utilización frecuente en la arquitectura ibérica. Son evidencias significativas para plantear una hipótesis de reconstrucción del monumento, del tipo gran plataforma cuadrangular, de altura no excesivamente elevada, coronada por una cornisa con moldura de gola egipcia, como las reconocidas en la necrópolis del Cabezo Lucero (Guardarmar del Segura, Alicante; Llobregat en Aranegui et alii, 1993), de grandes empedrados que cubren fosas cinerarias como bases de sustentación de grupos escultóricos o del tipo turriforme ${ }^{25}$, como en

dada la dificultad que implica diferenciar en algún caso, siguiendo criterios arquitectónicos, un monumento turriforme de un pilar-estela, se consideraron las dimensiones de las estructuras, interpretando como turriformes los que estaban dotados de una base que superaba los $2 \mathrm{~m}$ de lado (AlmagroGorbea, 1983, 248), como ocurre en el caso de Giribaile.

${ }^{25} \mathrm{El}$ ejemplo del monumento en forma de torre con gola figurada de Horta Major (Alcoy, Alicante. Almagro-Gorbea, 1982), aún reflejando elementos de la tradición arquitectóni- 
el conocido monumento de Pozo Moro (AlmagroGorbea, 1983).

Las dimensiones en planta de los cimientos de la construcción de Giribaile proporcionan una base de $5 \times 5 \mathrm{~m}$ de lado. Siendo prudentes, podemos plantear la existencia de 2 o 3 gradas que forman un plinto escalonado, habitual en este tipo de estructuras. Los ejemplos de los empedrados escalonados del sureste son significativos (Blánquez, 1990). Valorando las alturas de algunos de los sillares hallados junto a la estructura del monumento ( $f f$. supra) parece posible una elevación máxima en torno a 90 $95 \mathrm{~cm}$, si asumimos una triple grada para el monumento. Asimismo, las alturas de los sillares de gola reconocidos en Giribaile, muy fragmentados, se acercan a los $50 \mathrm{~cm}-46 \mathrm{~cm}$ en el caso del sillar de gola 1-. Estas cornisas en los repertorios conocidos, en general, rematan alzados de alturas variables. Nuestra hipótesis de reconstrucción del monumento se apoya en los ejemplos ya citados de plataformas, pilares o torres rematadas por este tipo de moldura de gola, en la cultura ibérica ${ }^{26}$. En el caso de Giribaile, sin olvidar la altura de la gola, parece necesario un alzado de, al menos, 1,5 m, para ser observada convenientemente, que sumados al alzado hipotético del plinto, constituyen en torno a 2,4 m de altura. El monumento, pues, en su conjunto - base escalonada, alzado y cornisa moldurada- podría alcanzar fácilmente, al menos, los $3 \mathrm{~m}$ de altura. Una propuesta gráfica, totalmente flexible, se ofrece en la figura 14. Existirían, no obstante, dos posibilidades condicionadas por el alzado de la estructura sobre el plinto, con 1,5 o $2 \mathrm{~m}$ de altura. No hemos de olvidar, además, el fragmento de la escultura hallada que complementaría, tal vez, este monumento y que por su estado de fragmentación no es posible integrar en esta reconstrucción hipotética. Finalmente, un pavimento de guijarros, externo al monumento, rodearía, formando una cenefa o una greca, la base de la construcción. Por sus dimensiones se trata de un monumento funerario de tamaño considerable, si lo comparamos con la mayoría de los grandes enterramientos oretanos exca-

ca funeraria ibérica, se sitúa, en nuestra opinión, en un horizonte cronológico avanzado con relación a esta cultura.

${ }^{26}$ Así, teniendo en cuenta la altura de otros monumentos funerarios mejor conocidos, dotados de cornisa de gola, hemos de recordar las dimensiones propuestas para el pilar de El Prado (Jumilla, Murcia) con $3 \mathrm{~m}$ sin remate escultórico e incluso 3.5 o $4 \mathrm{~m}$ con remate; el de Coimbra del Barranco Ancho (Jumilla, Murcia) con $1.74 \mathrm{~m}$ sin remate escultórico y 3,06 m con la escultura de toro; el de Arenero del Vinalopó con $2,5 \mathrm{~m}$ sin remate y $3,27 \mathrm{~m}$ con la escultura de toro; o el de Fuentecilla del Carrulo de Coy con $2 \mathrm{~m}$ de altura total sin remate y $2,6 / 2,7 \mathrm{~m}$ con la escultura de felino rematando el monumento. vados en las cercanas necrópolis de Cástulo, clasificados dentro del tipo de «enterramientos con grandes superestructuras», muy destruidos y situados en lugares que pudieran ser vistos a grandes distancias (García-Gelabert y Blázquez, 1992, 461-464), tales como la tumba del Cerrillo del Estacar de Robarinas ${ }^{27}$, construcción rectangular de la que sólo se conserva el lado norte de 3,5 m de longitud (GarcíaGelabert y Blázquez, 1988) o el monumento de Los Patos, de $4 \times 1,6 \mathrm{~m}$. Otra estructura interesante es el llamado túmulo de los Higuerones ${ }^{28}$, construcción rectangular de 4,32 × 6,36 m (Sánchez Meseguer, 1979, 416). La mayoría de las necrópolis oretanas que han evidenciado enterramientos con superestructura monumental poseen una cronología similar, desde finales del siglo $\mathrm{v}$ a mediados del IV a.C. (Blázquez y García-Gelabert, 1987), datación coincidente con el monumento de Giribaile.

En general, con respecto al grado de conocimiento del mundo funerario de los territorios de la alta Andalucía, como han señalado Ruiz, Rísquez y Hornos (1992, 400), el volumen de información existente al respecto no se corresponde en absoluto con la calidad de la misma. Existe un elevado porcentaje de excavaciones realizadas y materiales depositados en los museos o colecciones particulares. Sin embargo, lo que parece evidente es una gran riqueza en lo que se refiere a elementos monumentales, fundamentalmente de escultura. A los grandes programas escultóricos conocidos, procedentes del santuario heroico de El Pajarillo de Huelma (Molinos et alii, 1998), que dista unos $50 \mathrm{~km}$ de Giribaile, o el Cerrillo Blanco de Porcuna (Negueruela, 1990) se suma una serie de bloques monumentales y esculturas, en algunos casos de contextos funerarios y otros indeterminados ${ }^{29}$. No podemos olvidar

${ }^{27}$ En Estacar se documentaron también, como en Giribaile, algunos elementos de escultura fragmentados - bóvidos y équidos en este caso- reutilizados en los empedrados de las sepulturas (García-Gelabert y Blázquez, 1988, 231, fig. 60 y 75 , láms. XXII-XXX).

${ }_{28}$ Consta de un basamento con dos hiladas de piedra, sobre el que se levantaban tres hiladas de adobes dispuestos al exterior de forma escalonada. A la edificación se le ha supuesto una bóveda, por aproximación de hiladas. Se ha planteado que el monumento probablemente estuvo coronado por una estela. Entre el material hallado en el interior de la construcción se han recuperado piezas de cerámica ática.

29 Así, por ejemplo, son interesantes los hallazgos de Albánchez de Úbeda en relación con un posible monumento turriforme (Almagro-Gorbea, 1983, 237), aunque sin descartar definitivamente su interpretación como estela. En este mismo sitio se localizaron sendas esculturas de león y cérvido que podrían unirse al friso decorado y formar parte de un único monumento. Otras esculturas se han hallado en Arjona, Castellones de Ceal, Cerro de Alcalá, (Chapa, 1985, 76-81); Jódar (González Navarrete, 1987, 28), el Cortijo del Álamo, La Guardia, Santo Tomé de Villacarrillo o Villadompardo (Cha- 


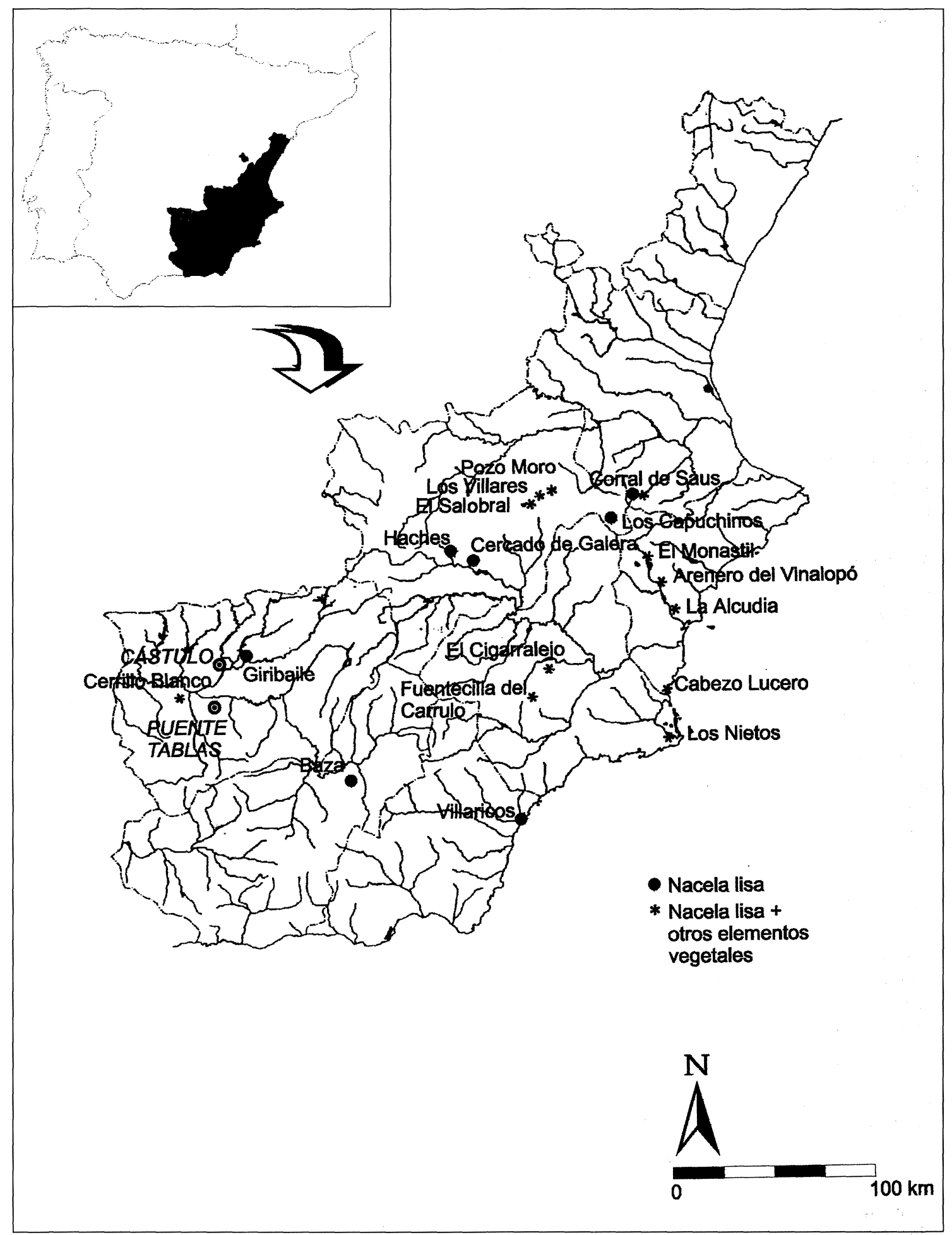

Fig. 15.-Dispersión de las golas lisas en la arquitectura ibérica monumental del sureste peninsular. 
los hallazgos de la Puente Quebrada del Guadalimar, que tradicionalmente han sido asignados a Cástulo. De este lugar se extrajeron dos leones labrados sobre sillares de esquina, a los que cabe añadir dos cornisas con nacelas decoradas datadas en el siglo IV a.C. (Almagro-Gorbea, 1983, 233257). Y como hallazgo arquitectónico, finalmente, cabe citar el capitel decorado del oppidum de Los Villares, situado $5 \mathrm{~km}$ al este de la localidad de Andújar, en el área de influencia de Obulco, relacionado con un pilar-estela (Moreno-Almenara, 1994).

El monumento de Giribaile, en el contexto del paisaje funerario peninsular, viene a sumarse a la reducida serie de grandes construcciones aristocráticas, de base cuadrangular y alzado, de altura variable, en forma de torre o gran plataforma. Una serie monumental que se extiende en la Península por las provincias de Alicante, Albacete, Jaén, Córdoba y Sevilla (Almagro-Gorbea, 1983; Chapa, 1985, fig. 14; Izquierdo, 2000), mal conocida debido al grado de conservación de los propios monumentos y/o la reutilización de sus componentes, la ausencia de contextos arqueológicos en gran parte de los casos considerados, así como la ambivalencia de algunas construcciones ${ }^{30}$. En el estado actual de nuestros conocimientos, es aventurado precisar grupos o variantes del monumento funerario en forma de torre, puesto que los ejemplos conocidos son realmente escasos. Giribaile, un siglo después de la construcción de Pozo Moro, atestigua la presencia de grandes estructuras monumentales en las necrópolis del Alto Guadalquivir, dotadas de esbeltas golas lisas (figura 15) y, tal vez, más imprecisamente, de esculturas complementarias. Muestra una imagen de la arquitectura funeraria ibérica de alto rango en un área donde, a pesar de los hallazgos de escultura exenta y en relieve, no está bien documentado este tipo de monumentos. En esta línea, pues, ha de valorarse esta construcción funeraria, dentro de un conjunto arqueológico complejo de gran interés y un territorio cuya dinámica es bien conocida.

pa, 1985). La mayor parte de estas piezas en bulto redondo han sido interpretadas como remates de pilares-estela, aunque en realidad se desconoce su funcionalidad precisa. Finalmente, en La Bobadilla, Mogón o Torredonjimeno, se hallaron esculturas antropomorfas (Ruano, 1987, III, 9-40).

${ }^{30}$ La existencia de tales monumentos se ha intuido, básicamente, a través de la documentación de sillares zoomorfos en altorrelieve que rematarían las esquinas de la construcción, como en el caso de Balazote o Bogarra (Albacete) y Elche (Alicante), así como esculturas semiexentas, como en La Rambla (Córdoba) o relieves con figuraciones - antropomorfas y/o zoomorfas-, como en Osuna o Estepa (Sevilla), Almodóvar del Río (Cordoba) o El Salobral (Albacete) que ornamentarían sus alzados.
Desde una perspectiva más global, una lectura social de los espacios funerarios puede ofrecer claves de análisis de los espacios de habitat. La sociedad ibérica se ha revelado, según las premisas actuales de la investigación, plural, jerarquizada y selectiva a la hora de enterrar a sus difuntos. La arqueología, en esta línea, ha demostrado la existencia de tumbas aristocráticas definidas por su monumentalidad constructiva y la manifiesta riqueza de sus ajuares. Estos monumentos suponen un punto de encuentro entre el mundo de los muertos y la sociedad de los vivos. Y la muerte constituye una ocasión única para afirmar el poder y ostentar un rango. El caso del monumento de Giribaile es paradigmático en este sentido. Interesa valorar aquí finalmente esta tumba monumental desde la óptica de su propio territorio y en relación con el asentamiento amurallado, puesto que simbólicamente refleja, en el espacio y en el tiempo, una construcción destacada. Se ubica en altura, en uno de los caminos de acceso a la fortificación y, según las fechas que indican los materiales de ajuar asociados, parece tener vigencia desde finales del v o comienzos del Iv a.C., momento en que arranca la secuencia arqueológica del oppidum de época ibérica. Este monumento en forma de gran plataforma cuadrangular revela, pues, el enterramiento, en la etapa fundacional del hábitat, de un aristócrata ibérico que exhibe su poder más allá de la muerte, frente a las murallas de Giribaile.

\section{BIBLIOGRAFÍA}

Abad, L., Sala, F. y Alberola, E., en prensa: «La necrópolis y el área sacra ibéricas de «Las Agualejas» (Monforte del Cid, Alicante)», Lucentum. Almagro-Gorbea, M., 1982: «El monumento de Alcoy», TP, 39, 161-211.

Almagro-Gorbea, M., 1983: «Pozo Moro. El monumento orientalizante, su contexto socio-cultural y sus paralelos en la arquitectura funeraria ibérica», $M M, 24,177-293$.

Almagro-Gorbea, M., y Rubio, F., 1980: «El monumento ibérico de Pino Hermoso, Orihuela (Alicante)», TP, 37, 345-362.

Almagro-Gorbea, A. y Ramos, R., (1986): «El monumento ibérico de Monforte del Cid». Lucentum, 5, 45-63.

Aranegui, C., 1992: La cerámica ibérica, Cuadernos de Arte Español, 34. Historia 16. Madrid.

Aranegui, C., Jodin, A., Llobregat, E., Rouillard, P. y Uroz, J., 1993: La nécropole ibérique de Cabezo Lucero. Guardamar del Segura. Alicante. CCV, 41. Madrid-Alicante. 
BlÁNQuez, J. y Antona, V. (Coords.), 1992: Las necrópolis. Congreso de Arqueología Ibérica. Serie Varia, 1, UAM.

Blázquez, J.M., 1975: Necrópolis de la Puerta Norte de Cástulo, Cástulo I, AAH, 8, 237-292.

Blázquez, J. Mª y García Gelabert, M. P.,1987: «La necrópolis de «El Estacar de Robarinas», Cástulo: Tipología de los enterramientos». APL, XVII, 177-188.

Castelo, R., 1995: Monumentos funerarios del Sureste peninsular: Elementos y técnicas constructivas, Monografías de Arquitectura ibérica. U.A.M.

Castillo, J.C. 1997: «Vilches, guardián de los pasos de Sierra Morena», Coleccionable del periódico Jaén, Pueblos y Ciudades, 136, 2711-2713.

CHAPA, T., 1985: La escultura ibérica zoomorfa. Ministerio de Cultura. Madrid.

Chapa, T., y Pereira, J., 1992: «La necrópolis de Castellones de Ceal (Hinojares, Jaén)», en Blánquez y Antona, 1992, 431-454.

Chapa, T.; Pereira, J., y Madrigal, A., 1993: «Mundo ibérico y mundo púnico en la Alta Andalucía», Actas del I Congreso de Arqueología Peninsular (Oporto, 12-18 de Octubre de 1993), vol. II, Trabalhos de antropologia e etnologia, vol. XXXIII, fasc. 3-4, 411-422.

CRuZ, M.L., 1990: «Necrópolis ibérica de Los Nietos (Cartagena, Murcia)», EAE. Madrid.

Domergue, C., 1987: Catalogue des mines et des fonderies antiques de la Péninsule Ibérique, Madrid, Publications de la Casa de Velázquez.

García-Gelabert, M.P., y Blázquez, J.M., 1988: Cástulo, Jaén, España: 1. Excavaciones en la necrópolis ibérica del Estacar de Robarinas (s. IV a.C), Oxford, BAR IS, 425.

García-Gelabert, M.P., y Blázquez, J.M., 1992: «Las necrópolis oretanas de Cástulo. Paralelos con las necrópolis ibéricas del sureste», en Blánquez y Antona, 1992, 455-472.

GónGORA, M., 1982 [1915-1916]: «Viaje literario», Don Lope de Sosa, año 1916, 5-8.

GonzÁlez Navarrete, J., 1987: Catálogo de la Escultura ibérica del Museo de Jaén. Jaén.

Gutiérrez, L.M., 1998a: El poblamiento ibérico en el curso medio del río Guadalimar, Tesis doctoral, Microfichas, Servicio de Publicaciones de la Universidad de Jaén.

Gutiérrez, L.M., 1998b: Roma y el poder local en el territorio del oppidum de Giribaile. Actas del Congreso Internacional Los Iberos, Príncipes de Occidente: estructuras de poder en la sociedad ibérica, Barcelona, 12-14 Marzo 1998, Ed. Fundación «La Caixa», 405-412.
Gutiérrez, L.M., y Royo, M.A., 1999: «Estudio de materiales procedentes del oppidum de Giribaile», Anuario Arqueológico de Andalucía de 1994, Actividades Sistemáticas, II, 119-124.

Gutiérrez, L.M.; Royo, M.A.; Barba, V., y Bellón, J.P., 1995: «Informe sobre la primera campaña de prospección superficial en el Guadalimar medio-hinterland de Cástulo», Anuario Arqueológico de Andalucía de 1992, Actividades Sistemáticas, II, 249-256.

GutiérRez, L.M.; Royo, M.A.; Barba, V., y Bellón, J.P., 1999a: «Informe de la segunda campaña de prospección superficial en el Guadalimar MedioHinterland de Cástulo», Anuario Arqueológico de Andalucía de 1994, Actividades Sistemáticas, II, 113-118.

Gutiérrez, L.M.; Royo, M.A.; Bellón, J.P., y BarBA , V., 1999b: «La Monaria. Análisis de un poblado del siglo I a.n.e. en el Guadalimar (Vilches, Jaén)», Actas del XXIV Congreso Nacional de Arqueología, vol. 4, 753-758.

IzQuiERdo, I., (2000): Monumentos funerarios ibéricos: Los pilares-estela. Serie de Trabajos Varios del S.I.P., 98, Valencia.

Molinos, M., 1997a: «La muralla ciclópea, símbolo del municipio de Ibros», Coleccionable del Periódico Jaén, Pueblos y Ciudades, 64, 1269-1271.

Molinos, M., 1997b: «Un patrimonio de primera importancia (Torredelcampo)», Coleccionable del Periódico Jaén, Pueblos y Ciudades, 123, 2451-2455.

Molinos, M.; Chapa, T.; Ruiz, A.; Pereira, J.; RísQuez, C.; Madrigal, A., Esteban, A., Mayoral, V. y Llorente, M. 1998: El santuario heroico de El Pajarillo (Huelma, Jaén). Servicio de Pubicaciones de la Universidad de Jaén.

Moreno-Almenara, M., 1994: «Un fragmento de capitel ibérico procedente del yacimiento de los Villares de Andújar (Jaén)». AAC, 5, 99-117.

Negueruela, I., 1990: Los monumentos escultóricos ibéricos del Cerrillo de Porcuna (Jaén). Estudio sobre su estructura interna, agrupamientos e interpretación. Ministerio de Cultura. Madrid.

Olmos, R., 1988: «Anotaciones iconográficas a las copas de Cástulo: conjeturas púnicas», en García-Gelabert y Blázquez, 1988, 315-324.

Olmos, R. et alii (1999): Los Iberos y sus imágenes. Ed. Cd-rom. Micronet/ CSIC. Madrid.

Pereira, J., 1988: «La cerámica ibérica de la cuenca del Guadalquivir. I. Propuesta de clasificación», TP, 45, 143-173.

Ramos, A., 1962: «Excavaciones en La Alcudia. Memoria de las practicadas durante 1953», NAH, V, 1962, 91-97. 
Royo, M.A.; Gutiérrez, L.M.; Bellón, J.P.; Barba, V. 1995: «Prospección arqueológica superficial de urgencia en la Presa de Giribaile (Jaén)», Anuario Arqueológico de Andalucía de 1992, Actividades de Urgencia, III, 408-414.

RuAno, E., 1987: La escultura humana de piedra en el mundo ibérico. Ed. E. Ruano Ruiz. Madrid.

Ruiz, A., 1995: Plaza de Armas de Puente Tablas: new contributions to the knowledge of Iberian town planning in the seventh to fourth centuries B.C. Simposium, The origins of urbanization in Iberia, London, 24-25 Februari 1994. Eds. Cunliffe, B. and Keay, S., London, 89-108.

Ruiz, A. y Molinos, M.,1993: Los iberos, análisis arqueológico de un proceso histórico, Barcelona, Crítica.

Ruiz, A. y Molinos, M.; Gutiérrez, L.M.; Royo, M.A. y Guidazzoli, A., 2000: Travel to the time of the Iberians, Virtual Reality in Archaeology,
Computer Applications and Quantitative Methods in Archaeology. CAA,Barcelona, 1998, Eds. Barcelo, J.A.; Forte, M. y Sanders, D.H., BAR, 843, 173-182.

Ruiz, A.; Rísquez, C., y Hornos, F., 1992: «Las necrópolis ibéricas en la Alta Andalucía», en Blánquez, y Antona, 1992, 397-430.

SÁnchez Meseguer, J.R., 1979: «Los Higuerones», en J.M. Blázquez (Ed.), Cástulo II, EAE, 105, Madrid, 416-426.

SANZ, R., 1997: Cultura ibérica y Romanización en tierras de Albacete: los siglos de transición. IAE. Albacete.

Servajean, F.; Servajean, G., y Castillejo, A. 1986: «De Giri a Guiribaile. Análisis de una posible correspondencia entre Giri y Guiribaile», BAEAA, 22, 37-46.

VAÑó, R., 1970: «Oratorio rupestre visigodo del cortijo de Valdecanales, Rus (Jaén), MM, XI, 213-223. 